\title{
Combining multiple predictive markers in stratified medicine
}

\author{
Richard Emsley ${ }^{1,2,3}$, Matthias Pierce ${ }^{1,2,3^{*}}$, Graham Dunn ${ }^{1,2,3}$ \\ From 3rd International Clinical Trials Methodology Conference \\ Glasgow, UK. 16-17 November 2015
}

Stratified medicine requires identifying predictive markers to determine differential treatment effects for subgroups. Ideally, these markers are then validated in prospective randomised trials. However, many of the methods for the analysis and validation of markers are based on there being a single marker. For example, a biomarker stratified trial design typically stratifies on a single binary marker. In many clinical scenarios, including recently funded MRC consortia, there are hypothesised to be multiple markers, often of different modalities such as clinical, genetic and imaging markers.

One issue in identifying any predictive marker is that an interaction effect is additive to the main effects of both treatment and the marker, which are also included in the analysis model. With multiple markers, if the effect size of one marker is much larger than any others, it alone may be sufficient for stratification of the population. If not, it may be appropriate to combine all markers into one single predictive biomarker.

Kraemer has proposed a method for combining multiple markers into a single combined measure, provided the markers are not highly correlated, which is likely when they share a common mechanism. We describe this approach, and extend it to account for multiple markers of different modalities and which are identified from different data sources. We will discuss the issue of choosing the appropriate scale of interaction (additive versus multiplicative), and how to incorporate multiple markers into prospective trial designs such as biomarker stratified designs.

Authors' details

${ }^{1}$ Centre for Biostatistics, Institute of Population Health, The University of Manchester, Manchester, UK. ${ }^{2}$ Manchester Academic Health Science Centre, Manchester, UK. ${ }^{3} \mathrm{MRC}$ North West Hub for Trials Methodology Research, Manchester, UK.

${ }^{1}$ Centre for Biostatistics, Institute of Population Health, The University of Manchester, Manchester, UK

Full list of author information is available at the end of the article
Published: 16 November 2015

doi:10.1186/1745-6215-16-S2-085

Cite this article as: Emsley et al:: Combining multiple predictive markers in stratified medicine. Trials 2015 16(Suppl 2):085.
Submit your next manuscript to BioMed Central and take full advantage of:

- Convenient online submission

- Thorough peer review

- No space constraints or color figure charges

- Immediate publication on acceptance

- Inclusion in PubMed, CAS, Scopus and Google Scholar

- Research which is freely available for redistribution

Submit your manuscript at www.biomedcentral.com/submit
() Biomed Central
C Biomed Central

C 2015 Emsley et al. This is an Open Access article distributed under the terms of the Creative Commons Attribution License (http:// creativecommons.org/licenses/by/4.0), which permits unrestricted use, distribution, and reproduction in any medium, provided the original work is properly cited. The Creative Commons Public Domain Dedication waiver (http://creativecommons.org/publicdomain/ zero/1.0/) applies to the data made available in this article, unless otherwise stated. 